\title{
Correction to: Principles of Distributed Database Systems
}

\section{Correction to:}

\section{T. Özsu, P. Valduriez,}

Principles of Distributed Database Systems, https://doi.org/10.1007/978-3-030-26253-2

The figures included in the original version of this book has been replaced. The figures have been updated throughout the book in this version of the book. The updated figures can be accessed through the link below:

https://cs.uwaterloo.ca/ ddbook/errata.html 

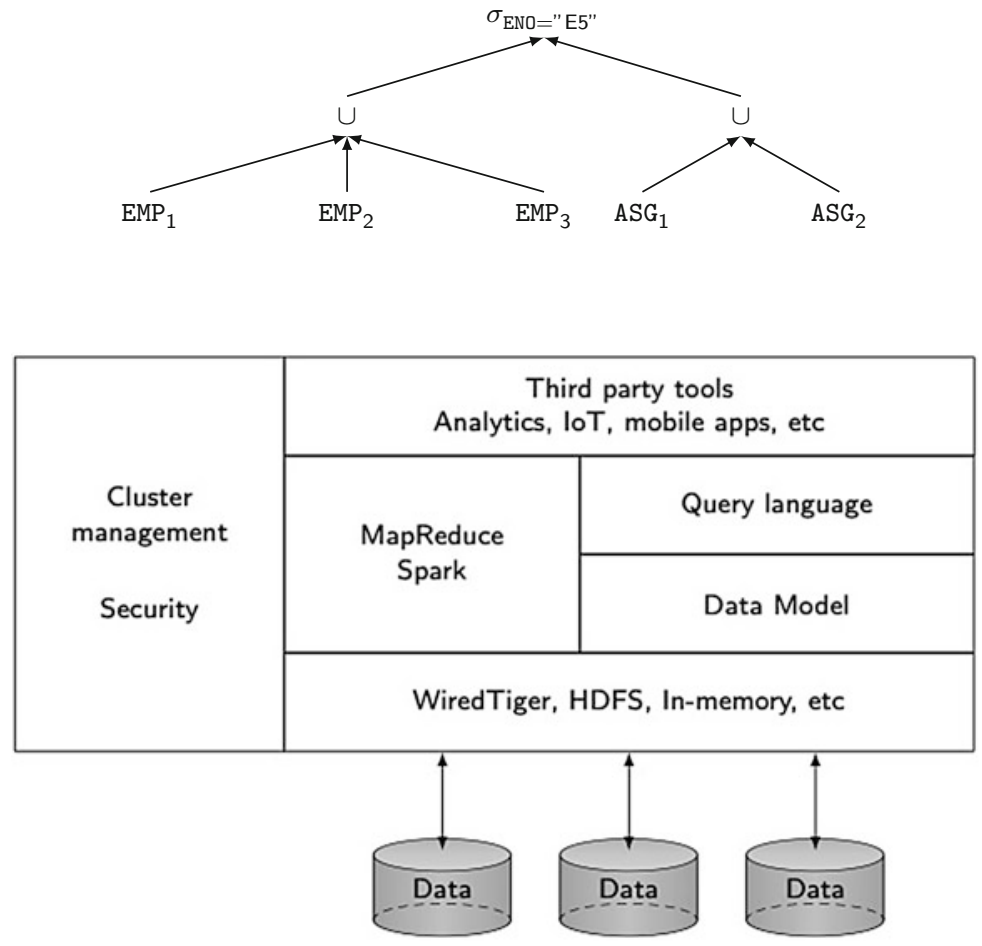